\title{
Sistemas de avaliação em larga escala e repercussões em diferentes contextos escolares: limites da padronização gerencialista
}

\author{
Large scale evaluation systems and its repercussions in different school \\ contexts: limits of managerialist standardization \\ Sistemas de evaluación en larga escala y repercusiones en diferentes \\ contextos escolares: límites de la padronización gerencialista

\section{ANDRESSA AITA IVO \\ ÁLVARO MOREIRA HYPOLITO}

Resumo: O artigo discute como os sistemas de avaliação em larga escala, em especial a Prova Brasil, repercutem em espaços escolares diferentes. A partir de estudo qualitativo em duas escolas, os relatos dos gestores e professoras entrevistadas mostram como os sistemas de avaliação em larga escala têm assumido importância no contexto educacional. A política de índices de qualidade desconsidera as especificidades locais, reforça a competição e a busca desenfreada das escolas por resultados. Os resultados apontam que as políticas gerencialistas de avaliação não garantem a qualidade da educação.

Palavras-chave: Avalição em larga escala; IDEB; Escola; Gerencialismo.

\begin{abstract}
This article discusses how large-scale evaluation system, particularly Prova Brasil - Brazil Exam, have influenced different school spaces. Based on a qualitative study in two schools, the reports of principal, supervisors and teachers interviewed show how large-scale evaluation system has assumed a relevant role in the school context. The educational policies of quality based on index disregards local specificities, reinforce competition, and the unbridled pursuit of schools by results.
\end{abstract}

Keywords: Large-scale Evaluation; IDEB; School; Managerialism.

Resumen: El artículo discute cómo los sistemas de evaluación a gran escala, en especial el Examen Brasil, repercuten en espacios escolares diferentes. A partir de un estudio cualitativo en dos escuelas, los relatos de los gestores y profesoras entrevistadas muestran cómo los sistemas de evaluación a gran escala han asumido importancia en el contexto educativo. La política de índices de calidad desconsidera las especificidades locales, refuerza la competencia y la búsqueda desenfrenada de las escuelas por resultados. Los resultados apuntan que las políticas gerencialistas de evaluación no garantizan la calidad de la educación.

Palabras clave: Evaluación a gran escala; IDEB; Escuela; Gerencialismo. 


\section{INTRODUÇÃO}

Nas últimas décadas, houve profundas reestruturações no estado capitalista e nas políticas educacionais, a partir da crise do Estado de Bem-Estar Social e da consolidação do Estado Neoliberal. A educação tem desempenhado um papel muito importante para a constituição da hegemonia neoliberal e tem sido modificada de forma muito abrangente no direcionamento para o mercado. Tais mudanças estão discutidas de forma muito interessante no livro de Dardot e Laval (2016) sobre o que os autores denominam de a nova razão do mundo.

A educação vem sendo globalmente reorganizada a partir de recomendações políticas votadas para o mercado e orientadas pela eficiência, qualidade, parcerias público-privadas, redes de governança, processos muito bem discutidos em Ball (2008; 2013; 2014), Laval (2004) e Lessard e Carpentier (2016), referências que serviram de base teórica para nosso entendimento das políticas educativas no Brasil.

Tais transformações estruturais do estado introduziram um novo modelo de gestão, em substituição ao estado burocrático-profissional, como sinônimo de eficiência, que ficou conhecido como Nova Gestão Pública ${ }^{1}$, que de forma ampla significa a introdução do modelo gerencial capitalista para a administração da coisa pública, o que passaremos a denominar gerencialismo. Na educação, em especial, tem havido uma hegemonia dessa concepção e as políticas educativas têm sido fortemente influenciadas, tanto nas políticas mais amplas de gestão da educação para o mercado quanto no contexto de gestão escolar (CARVALHO, 2000).

Parte significativa dessas políticas se baseiam na implantação de metas, índices, resultados, avaliação. Em especial, os modelos de avaliação em larga escala e as políticas de prestação de contas, bônus de gratificação, parcerias públicoprivadas, terceirização e outras formas de gerência na busca da qualidade do sistema escolar.

Ainda que não haja um consenso acerca da implantação de sistemas de avaliação em larga escala no sistema educacional e existam divergências quanto aos efeitos dessas avaliações sobre o contexto escolar, é inegável a influência que as avaliações padronizadas têm assumido nas últimas décadas nas gestões públicas. O sistema educacional brasileiro apresenta uma série de exames nacionais padronizados nos diferentes níveis e modalidades de ensino. Dentre as críticas a tais modelos de avaliação, argumenta-se que as avaliações padronizadas

1 Como exemplo, ver VERGER e NORMAND (2005). 
não levam em consideração o contexto escolar, ainda que diferentes pesquisas já tenham demonstrado a relevância do contexto escolar na aprendizagem dos alunos (VIANA, 2005; NOGUEIRA et al, 2009).

Nessa direção, este artigo tem como objetivo compreender de que maneira os sistemas de avaliação em larga escala, especialmente a Prova Brasil, têm repercutido em diferentes espaços escolares. As discussões apresentadas tiveram como contexto de investigação duas escolas da rede municipal de ensino de um município de médio porte da região central do Rio Grande do Sul. Os dados coletados são referentes a políticas educacionais desenvolvidas no período de 2009 a 2012. O critério mais definitivo para a escolha dessas escolas foi baseado no desempenho de cada uma delas em relação ao Índice de Desenvolvimento de Educação Básica (IDEB)², tendo sido, assim, selecionadas uma escola com desempenho acima da média nacional e outra com desempenho inferior à média nacional.

Os dados emergiram de entrevistas semiestruturadas realizadas com profissionais dessas escolas. A fim de preservar a identidade dos sujeitos participantes da pesquisa, utilizamos uma nomenclatura fictícia. Os membros da equipe gestora da SMED foram identificados como gestora, nome fictício e sigla SMED, sem distinção para o cargo ocupado. As gestoras das escolas foram denominadas como gestora, nome fictício e a sigla da escola em que trabalhavam (EV para a Escola Verde e EA para a Escola Amarela). As professoras tiveram os nomes substituídos por nomes fictícios, acompanhados pela sigla da escola em que trabalhavam. Optamos por não fazer distinção de gênero; assim, todos os sujeitos foram nomeados como sendo do gênero feminino.

\section{OS SISTEMAS DE AVALIAÇÃO E A POLÍTICA DE GESTÃO DA SMED: SEUS EFEITOS E REPERCUSSÕES NOS CONTEXTOS DA ESCOLA VERDE E DA ESCOLA AMARELA}

Em 2009, a Secretaria Municipal de Ensino deu continuidade a um plano de ações ${ }^{3}$ que tinha no IDEB seu principal eixo norteador, o que demonstrava a

2 O IDEB é calculado com base em dois componentes: a taxa de rendimento escolar (aprovação e evasão) e médias de desempenho das escolas na Prova Brasil (exame nacional padronizado, aplicado para classes de $5^{\circ}$ e $9^{\circ}$ anos, das escolas da rede de ensino público). O objetivo é alcançar até 2021 a meta do padrão educacional dos países da OCDE equivalente à avaliação do PISA - que é um programa internacional de avaliação dos estudantes. Isso significa sair da média nacional de 4.6 - séries iniciais - e 4.0 - séries finais do Ensino Fundamental, registradas em 2009, para um IDEB igual a 6.0 em ambos os níveis.

3 Este município adotou, a partir de 2009, todo um conjunto de ações baseado em políticas gerencialistas similares às indicadas pela lógica da NGP. Essas políticas foram analisadas com mais detalhes em outro trabalho (IVO e HYPOLITO, 2015), por isso não serão aqui apresentadas. 
relevância que os sistemas de avaliação externa assumiam naquela conjuntura para a SMED e no cenário da política municipal, como mostra o seguinte depoimento:

Na verdade, é como eu te disse, o trabalho da gestão pedagógica está atrelado a um plano de
governo [.... Bem, este trabalho partiu do governo municipal, a primeira coisa que a gente foi atrás
era o que este governo municipal pretendia para a educação, o que as equipes que me precederam
já tinbam feito e o que me caberia fazer. A gente fica atrelado a um plano de governo, sim, em
termos pedagógicos nós estamos preocupados com politicas públicas nacionais, o pedagógico tanto
éplano de governo, como também plano de politica nacional de educaşão que tu tens que atender
(gestora Magnólia; SMED)

O depoimento da gestora Magnólia indica o modelo de gestão assumido pela SMED, o qual possuía um plano de ações inserido num plano de governo, que, dentre seus objetivos, visava a atender às exigências das avaliações externas, especialmente a Prova Brasil. Na tentativa de melhorar a posição do município em relação ao IDEB, várias ações foram desenvolvidas pela SMED; todavia, como adverte Paz e Raphae (2012):

\begin{abstract}
Duras críticas têm sido tecidas contra esse tipo de política de avaliação visto que desconsideram que parte dos problemas educacionais advém do próprio formato do projeto ideológico neoliberal, no qual se reduz a qualidade à igualdade de acesso às escolas, mas, em contrapartida, se estimula a competição e o ranqueamento entre elas, gerando espaços para ricos e espaços para pobres, segregando ainda mais as camadas populares no interior dos sistemas de ensino (p. 58).
\end{abstract}

O Estado vem determinando, por meio dos princípios e das bases da avaliação externa, um modelo de gestão em que as redes de ensino são chamadas a prestar contas, a criar ações e estratégias a fim de melhorar os indicadores educacionais. Com isso, observa-se uma política indutora, a partir do contexto de políticas nacionais que interpelam o contexto de políticas locais (BALL, 1994).

A imposição de metas educacionais traçadas para as redes de ensino, e para cada escola tem levado as redes de ensino a construir estratégias e planos para melhorar os resultados municipais, com efeitos significativos para os contextos escolares, como se observou na rede municipal de ensino investigada. No entanto, a maneira como cada rede de ensino responde às demandas das políticas nacionais (criação de políticas de bonificação, provas municipais, indicadores municipais, simulados, etc.) pode reforçar ainda mais uma perspectiva gerencialista, com centralidade das avaliações externas no plano de ações municipais.

O depoimento da professora Marisol, a seguir, demonstra sua insatisfação com esse modelo municipal de caráter gerencialista, que coloca em evidência 
os conceitos de eficiência, produtividade e eficácia e que desconsidera o papel dos docentes no desempenho educacional, como suas preocupações, interesses, concepções e experiências.

\begin{abstract}
Ah, eles só se preocupam com números. Eles querem fazer o IDEB aumentar, mas na contramão. Educaşão de qualidade se faz com investimento, educação não é economia, eles querem economizar dinheiro, mas ao mesmo tempo querem que o IDEB cresça. Para cobrar IDEB alto tem que investir em educação e isso não existe na cidade, só existe a cobrança em cima dos diretores e dos professores. A gente tem que aprovar alunos, mas que qualidade é essa de aprovar alunos sem condições? ... querem que a gente faça milagre, ganhando mal, sem muitas condições, mas que melhore o IDEB (professora Marisol; EV).
\end{abstract}

Como sustenta Ball, em entrevista concedida a Mainardes e Marcondes (2009), as políticas educacionais "são pensadas e, em seguida, escritas com relação às melhores escolas possíveis, com pouco reconhecimento de variações de contexto, em recursos ou em capacidades locais" (p. 306). Nessa direção, os seguintes relatos fazem referência aos diferentes contextos escolares que compõem a rede municipal de ensino:

Nós temos escolas, mais próximas da base área e da universidade, que possuem um tipo de clientela diferente da nossa, que está numa vila bem afastada da cidade. E aí nós vamos comparar o desempenho daqueles alunos com o dos nossos daqui? Os nossos vão sempre estar em desvantagem, mas a prefeitura não discute isso conosco (professora Marisol; EV)

A nossa realidade é diferente, os alunos são do entorno da nossa região, é um bairro diferenciado. A gente não pode simplesmente anular este dado, porque é um fator diferencial também (gestora Amélia; EA).

Como demonstram diversos estudos, o desempenho cognitivo dos alunos em sistemas de avaliação em larga escala depende de uma teia complexa de fatores, envolvendo fatores intra e extraescolares, tais como características sociais, econômicas e culturais das famílias, habilidades dos alunos, dentre outros.

A fim de melhor compreendermos como esses fatores podem interferir no desempenho dos alunos nas avaliações externas e melhor analisarmos como as ações da SMED podem ter influenciado diferentes espaços escolares, elencamos algumas categorias centrais para a análise dos contextos investigados - Escola Verde e a Escola Amarela - assim organizados: população atendida e participação da comunidade escolar; infraestrutura e condições de trabalho; quadro docente e gestão escolar. 


\title{
CONTEXTOS ESCOLARES, PERFIL DOS ESTUDANTES E PARTICIPAÇÃO DA COMUNIDADE ESCOLAR
}

Assim como Ferrão e Fernandes (2003, p.1), entendemos que sempre há que se ter em consideração "que a contribuição da escola no desenvolvimento intelectual e social das crianças está condicionada às características extraescolares que essas carregam" (p. 1). Nesse sentido, o seguinte depoimento pode ilustrar o contexto educacional em que está inserida a Escola Verde:

\begin{abstract}
A grande maioria dos alunos são miseráveis, moram em condições precárias, muitas vez̧es não têm uma roupa limpa e seca para vestir, vão descalços para a escola, a gente sabe que são subnutridos, que passam fome, não têm aquele material mínimo para assistir a aula. Às vezes eles chegam só com o corpo, dai o professor tem que dar uma folha de papel, um lápis e uma borracha, porque os alunos não têm, eles não têm este material básico. E por mais que a gente diga que qualquer pessoa possa aprender em qualquer condição, é impossivel que isso não tenha influência, eu acho que tem (professora Hortência, EV).
\end{abstract}

O contexto da Escola Verde é um contexto de grande vulnerabilidade social, com graves problemas sociais e econômicos. De modo geral, os alunos são provenientes de famílias desfavorecidas que vivem em condições precárias. Nesse contexto, os professores e os gestores são chamados e desafiados a educar essa população. Diferentemente, a Escola Amarela possui outro contexto social e educacional:

A nossa clientela aqui não é de periferia, nós temos alunos que vêm transferidos de outras escolas, que são alunos mais carentes, mas a maioria dos alunos são de classe média, os pais trabalham na universidade, na base aérea (gestora Maria; EA)

Com contextos educacionais tão diferentes, o que não é raridade nessa rede municipal de ensino, é no mínimo paradoxal que uma gestão tão preocupada com a melhoria da qualidade da educação atribua tanta ênfase aos sistemas de avaliação em larga escala, desconsiderando as disparidades existentes entre as escolas. Como afirma Santos (2002), “o docente só poderá realmente assumir sua função e seu papel de acordo com aquilo que é posto pelas políticas públicas no campo educacional, quando forem criadas condições para que ele possa dedicarse à solução dos problemas educacionais" (p. 364).

Como é sabido, o papel da comunidade escolar é de grande relevância para o sucesso de políticas educacionais e para o desenvolvimento de uma educação de qualidade. Nesse sentido, podemos observar que a Escola Verde tem na participação da comunidade escolar um de seus principais desafios, como apontam os seguintes relatos: 
Há uma participação bastante ativa de algumas familias nas atividades da escola, mas há responsáveis que nunca comparecem, sequer para receber os boletins no final do ano letivo. Há pais que levam as crianças todos os dias à porta do prédio, conversam com os professores ou com a diretora, perguntam sobre o desempenho dos filhos, demonstram valorizar a educação, a escola e o trabalho dos educadores, independentemente de sua própria escolaridade (alguns são analfabetos). Mas há pais que os professores nem conbecem, embora lecionem para os filhos durante anos. Há casos extremos em que os responsáveis desconbecem até o ano que as crianças estão cursando (professora Hortência; EV)

Mas tu percebes que aquela criança que tem problema de assiduidade, de aprendizagem, de comportamento e disciplina, a família dessa criança dificilmente participa. Em relação a outras tu percebes que eles vêm, que estão presentes nas reuniões de pais, vêm bastante pais e isso é uma coisa que cresceu bastante. Eu considero boa a participação deles, porém as famílias que realmente precisariam vir não vêm. Essas famílias têm em média cinco filhos matriculados na escola, tem um no $1^{\circ}$, um no $3^{\circ}$, um no $5^{\circ}$, um no $7^{\circ}$, um no $8^{\circ}$, todos são da mesma família, a gente já conbece aonde está o problema, a gente só não sabe é como solucionar este problema, a gente até tenta, mas não consegue (gestora Olga; EV).

A Escola Amarela conta com ampla participação da comunidade nas atividades propostas pela escola. Esta passagem demonstra um pouco isso:

\begin{abstract}
Este eu acho que é outro diferencial nesta questão dos nossos resultados, porque bá uma grande participação, envolvimento das famílias, claro que não é de 100\%, a gente também tem problemas com pais que não participam, mas acho que até pelas reuniões que participo com os coordenadores de outras escolas, eu vejo que na nossa comunidade tem um engajamento muito bom. [...] por serem famílias com maior nivel de estudo, também dão uma importância maior para a educação, então eles se interessam, eles buscam alternativas junto com a gente e principalmente incentivam os filhos. Nos eventos que a escola faz eles participam direto, os eventos promovidos pela escola são sempre um sucesso, e nisso também que se consegue muita coisa de material didático, porque é com recursos que a própria escola angaria, que faz, toda a diferença no desenvolvimento dos alunos em sala de aula (gestora Amélia; EA).
\end{abstract}

O depoimento mostra um comprometimento da comunidade em relação à escola, um sentimento de pertença que faz com que a comunidade seja parceira da escola, as conquistas não são da escola, mas de todos os envolvidos.

O trabalho que as professoras desenvolvem com os alunos da Escola Verde vai muito além do ensino habitual das escolas, mas as condições de vida a que os alunos estão submetidos fora do âmbito escolar têm forte influência no cotidiano escolar. Com isso, é muito provável que o desempenho desses alunos nas avaliações externas não seja o esperado pela SMED, mas as conquistas desses alunos, das professoras e da gestão escolar vão muito além de dados quantitativos frios. 
Eu acho que o que deveria ser visto, o que tinha que ser considerado é o crescimento da escola [...]. As conquistas da nossa escola não se resumem ao resultado de uma prova, é muito mais que isso, a nossa conquista está em levantar a autoestima de um aluno, da aluna não engravidar, de não desistir de estudar, de permanecer na escola, para gente isso é um crescimento que em nada muda o IDEB (gestora Olga; EV).

Olha o nosso IDEB é baixo, mas o que a gente percebe com isso é que não depende somente do professor, há $n$ fatores que influenciam. E como se calcula o IDEB? É o resultado da Prova Brasil e ofluxo, e dai faz a média. [...] não é que a gente queira que eles se saiam mal nas provas, mas o problema é que eles têm muita dificuldade de aprendizagem, é fator econômico, é fator social, é fator familiar, tudo influencia na aprendizagem, e aqui é um local muito complicado (gestora Neuza; EV).

Os depoimentos acima fazem referência a problemas sociais de diversas ordens que aparecem na Escola Verde e atingem a maioria dos alunos da escola. Com a ausência de políticas públicas sociais, o trabalho desenvolvido pelas professoras e gestores da Escola Verde se centra, muitas vezes, em resolver ou contornar problemas sociais, por meio de atividades assistencialistas e sociais que reduzem o tempo para o trabalho pedagógico e escolar de organização e sistematização dos conteúdos que são avaliados pelos exames padronizados.

Do mesmo modo, as expectativas que os alunos possuem em relação a seu futuro e à escola fazem diferença no comprometimento dos alunos com os seus estudos e com a maneira como percebem e veem a escola, conforme ilustram os seguintes relatos referentes às duas escolas:

\footnotetext{
Eu acredito que uns $80 \%$ dos alunos já pensam nos concursos, porque a nossa clientela aqui faz. a prova para o técnico, mas tem outros que não querem, mas sabem que se fizerem um primeiro grau bem feito, farão um segundo grau bom, $[. .$.$] depois tudo fica mais fácil, então eles vão se$ preparando ao longo do tempo (professora Rosa; EA)

Eu não noto nem este objetivo neles, eles não têm essa aspiração de terminar o ensino médio. Quando se fala em universidade para eles, parece uma coisa de outro mundo, eles não querem estudar, não têm incentivo, um modelo a seguir, eles não veem isso na família ou na comunidade (professora Hortência; EV)

É uma realidade muito complicada porque eles não enxergam na educação algo que possa fazer melhorarem de vida... se hoje en tenho para comer, ótimo, en não preciso me preocupar com amanhã. (gestora Olga; EV).
}

Para os alunos da Escola Amarela, de modo geral, a educação é entendida como um meio para galgar um futuro melhor; os alunos estão no Ensino Fundamental e já se preparam para o Ensino Médio. Trata-se daquilo que Mariano Fernández Enguita (1989) denominou identificação expressiva (no sentido de uma identificação com os valores culturais e políticos da escola) e instrumental (no sentido de uma identificação técnico e profissional) com a escola. A educação para os alunos da Escola Verde possui outro significado, pois não se identificam 
nem expressivamente nem instrumentalmente com os valores culturais e técnicos da escola. Esses são fatores de determinação mais ampla do que os testes pretendem provar ou medir.

\section{INFRAESTRUTURA E CONDIÇÕES DE TRABALHO}

Quanto à infraestrutura, ambas as escolas apresentam condições similares; são bem equipadas e dispõem praticamente da mesma estrutura física e dos mesmos recursos didáticos. A infraestrutura das escolas da rede municipal de ensino tem, de modo geral, recebido atenção da SMED, que, desde 2010, buscou realizar um trabalho de reformas e ampliação da rede,

\footnotetext{
Nós começamos um trabalho de recuperação da escola, da parte física, do espaço escolar, dando uma manutenção que há muitos anos as escolas não viam. Tu encontravas escolas com um padrão muito bom e outras que dava pena. Dai começamos um trabalho excepcional de reformas [...]. Num segundo momento estabelecemos que a sala de aula deveria ser um lugar atrativo, equipado (...) se tu andares pelas escolas do município todas possuem computadores, data show, uma biblioteca contemporânea, ou seja, deixamos a sala de aula atrativa e esse foi um investimento muito pesado em termos financeiros (gestora Joana; SMED).
}

Como apontam alguns estudos (Franco et al, 2007; Palermo, Silva e Novellino, 2014, entre outros), a infraestrutura física da escola produz um efeito positivo sobre o desempenho dos alunos; contudo, "a pura e simples existência dos recursos escolares não é condição suficiente para que os recursos façam diferença: faz-se necessário que eles sejam efetivamente usados de modo coerente no âmbito da escola" (FRANCO et al, 2007, p. 282). Com essa preocupação, a gestora da Escola Amarela busca promover várias atividades a fim de angariar fundos para realizar melhorias na infraestrutura da escola, bem como proporcionar boas condições de trabalho para os professores,

\footnotetext{
É um trabalho conjunto entre a escola e a comunidade, eu acho que não adianta pensar que é só porque a nossa escola é mais centralizada que a escola de periferia não tem condições, não. Eu acho que as escolas do município todas têm os mesmos recursos, isso depende muito da administração, a gente não espera só pelo que a prefeitura nos dá, a gente faz muitas promoções e, por isso, também que a escola há muitos anos já tem data show, ar condicionado em todas as salas, tudo isso foi conseguido com recurso próprio. Eu acho que isso também estimula o aluno e o professor, ao chegar numa sala de aula e ter recursos para trabalhar com o aluno, nós temos sala de informática, temos sala de recursos, temos condiçoes de trabalho (gestora Maria; EA).
}

Muito embora o relato da gestora Maria demonstre seu comprometimento com a escola e sua preocupação em proporcionar boas condições de trabalho para os professores, há que se considerar o apoio e a adesão da comunidade local, frente a suas atividades e iniciativas. 
No caso da Escola Verde, os professores e gestores têm como desafio justamente preservar o patrimônio da escola, deteriorado não somente pelos alunos como também por membros da comunidade local, como apontam os seguintes relatos:

\begin{abstract}
A Escola Verde é uma das mais novas da Rede Municipal, com apenas sete anos, é considerada ideal no aspecto da infraestrutura. [...] um ponto negativo a esse respeito é a depredação, realizada não somente pelos próprios alunos, mas também por indivíduos de fora, que têm acesso ao prédio, porque a escola não possui muro externo. Tem sido difícil desenvolver nos alunos o respeito pelos bens públicos (Professora Hortência; EV).
\end{abstract}

Outro fator relevante refere-se à população atendida pela Escola Verde. $\mathrm{O}$ fato de atender estudantes com graves problemas econômicos e sociais, pode, como temos assinalado, tornar o trabalho pedagógico e escolar com mais dificuldade e desafios, que produzem diferentes efeitos sobre o trabalho das professoras.

Quando en fui para a Escola Verde levei um choque. Acho que eu levei um meio ano para me adaptar, para comeşar a me comunicar com as crianças e entender qual o tipo de linguagem eu precisava utilizar para que me entendessem. Eu aprendi muito com eles, agora eu gosto [...], mas tive bastante dificuldade para me adaptar, porque eu nunca tinha trabalhado com criancas assim, tão pobres, crianças que não tinham material ou que iam para aula com fome, on que iam de bermuda e camisetinha num frio de 5 graus no inverno. Nunca tinha me acontecido isso. Crianças que não conseguiam entender o que eu falava, porque eles não entendem. Dependendo da classe social, com condições muito precárias, se não tem uma família que dê suporte, o vocabulário deles é tão restrito que eles não conseguem entender o que a gente fala. Tem que tomar cuidado com as palavras que tu vais usar, como é que tu vais dizer as coisas, para que eles possam entender qual é o teu objetivo, o que tu estás pedindo" (professora Hortência; EV).

O relato da professora Hortência faz alusão à dificuldade que as professoras possuem em trabalhar na Escola Verde. Dificuldades que não estão atreladas às condições de infraestrutura da escola, que são boas, mas relacionadas às características sociais, culturais e econômicas da população atendida pela escola. Os alunos e as alunas convivem com inúmeras condições desfavoráveis, do ponto de vista social, econômico, afetivo e intelectual, que produzem efeitos para o trabalho docente. De acordo com estudos realizados por Érnica e Batista (2012) "as escolas situadas em territórios de alta vulnerabilidade acumulam desvantagens e tendem a se consolidar como locais de 'decantação' dos diversos problemas das escolas em posição de vantagem” (p. 656).

O contexto no qual as escolas estão inseridas tem repercussões nos resultados das instituições de ensino nas avaliações externas. Embora isso nos pareça óbvio e já tenha sido denunciado em outros estudos, um dos grandes 
problemas dos sistemas de avaliação em larga escala e das ações da SMED consistem, justamente, em não considerar as diferenças entre os contextos escolares, como mostram os seguintes relatos:

\begin{abstract}
A Secretaria de Educação fica preocupada com o baixo IDEB de muitas escolas, mas nós não encontramos uma justificativa para isso, uma vez que a cidade tem escolas com recursos, as escolas estão fisicamente bem estruturadas e com recursos suficientes e até bem distribuidos para aprendizagem, como laboratório de informática, como equipamentos eletrônicos, a estrutura básica, merenda, transporte, enfim todos os investimentos [...]. Nós temos escolas com $100 \%$ dos professores com pós-graduação e o IDEB é baixíssimo. Isso nos preocupa muito e nós entendemos que parte disso pode ser até pela própria falta de compreensão da politica pública de avaliação externa, e por isso esse movimento de negação, de resistência. É um corpo docente extremamente qualificado. Isso não justifica ou pelo menos derruba o mito de que a qualificação do professor é garantia de qualidade na escola, porque nós temos escolas com 100\% dos professores com pósgraduação e IDEB baixíssimo (Gestora Magnólia; SMED)

É inconcebivel que tu tenhas uma rede com 1.500 professores e, destes, $1.100 \mathrm{com}$ mais do que a graduação, e como é que tu tens 24 escolas abaixo do IDEB. Não tem como! Daí, então, o que a gente fez? Trabalhamos em cima destas escolas, fazendo simulados, demos cursos para os professores, trabalhamos com os alunos, trabalhamos os conteúdos, basicamente com letramento, porque nós trabalhamos em cima da Prova Brasil [...]. Então, se há investimento, se há um corpo docente bem qualificado, se tu tens as crianças bem alimentadas com merendas maravilhosas, se tens o professor valorizado, enfim, tu tens que ter resultados. Você ainda não tem uma uniformidade na rede, você vai encontrar escolas com um desempenho muito acima da média, e outras abaixo da média e o nosso trabalho está focado em primeiro dar uma uniformidade para a rede (Gestora Joana; SMED).
\end{abstract}

Esses depoimentos entrelaçam a qualificação docente e a infraestrutura das escolas com o desempenho dos alunos nas avaliações externas e desconsideram que os contextos nos quais os sujeitos estão inseridos não são os mesmos. A nosso ver, diversas variáveis que interferem no processo de aprendizagem dos alunos não estão sendo consideradas. Julgamos que, para pensarmos em qualidade da educação, não podemos simplesmente ignorar os fatores intra e extraescolares que interagem e influenciam o processo educativo. Ideia que é reforçada por Dourado e Oliveira (2009), quando afirmam que para uma análise da qualidade educativa "tem que se considerar os diferentes atores, a dinâmica pedagógica, os processos de ensino-aprendizagem, os currículos, as expectativas de aprendizagem, bem como os diferentes fatores extraescolares que interferem direta ou indiretamente nos resultados educativos" (p. 205).

Identificamos que os fatores extraescolares presentes no contexto em que a rede municipal de ensino investigada está inserida são simplificados ou ignorados pelos gestores. Há muito aprendemos isso com Bourdieu (1989): "tratando todos os educandos, por mais desiguais que sejam eles de fato, como iguais em direitos e deveres, o sistema escolar é levado a dar a sua sanção às desigualdades iniciais diante da cultura" (p. 10). 
Tendo em vista as desigualdades sociais, culturais e econômicas que interpelam a comunidade escolar da rede municipal de ensino, seria muito pretensioso esperar resultados iguais entre as escolas com base em um sistema de avaliação padronizada.

\section{FORMAÇÃO DAS PROFESSORAS E GESTORES DAS ESCOLAS VERDE E AMARELA}

No que se refere à formação docente, o trabalho em ambas as Escolas, Verde e Amarela, é muito semelhante. Ambas possuem um quadro docente qualificado, o que, na realidade, é característica de toda a rede municipal de ensino, conforme aponta a gestora Magnólia:

Nós temos um quadro de recursos bumanos extremamente bem qualificado, nós temos hoje 1558 professores na rede, 1131 têm pós-graduação, 252 têm graduação e apenas 18 não têm graduação; temos 127 mestres e alguns doutores.

No caso da Escola Amarela, apenas três professoras, em um total de 23, não possuem especialização. A escola possui três professoras com Mestrado. $\mathrm{Na}$ Escola Verde, a realidade é muito similar: apenas uma professora, dentre 54, não possui especialização e duas professoras são Mestres. A grande diferença entre as escolas está relacionada à carga horária docente e ao tempo de serviço na mesma escola, dois aspectos de grande relevância para a qualidade da educação.

A Escola Amarela possui, nesse sentido, um grande diferencial, pois a maioria das professoras desempenha 40 horas na escola.

E este é um ponto diferencial da nossa escola: o nosso quadro de professor. Porque a maioria tem 40 horas. (...) são professores que estão aqui o dia todo, estão envolvidos, estão comprometidos com a escola e com todo o trabalho, os professores que dão aula no $1^{\circ}$ ano da manhã, dão aula no $1^{\circ}$ ano da tarde. Agora, isso foi uma coisa que nós conseguimos ao longo do tempo, formar um quadro de professor que está junto há muito tempo, isso dá outra qualidade ao trabalho (gestora Amélia; EA).

Como as professoras têm 40 horas na Escola Amarela, acompanham todo o cotidiano escolar e desenvolvem um trabalho em conjunto, não só com a equipe gestora, mas também com as turmas para as quais ministram aulas. Como destaca a gestora Amélia, algumas professoras trabalham com o mesmo ano tanto no turno da manhã, como no turno da tarde, o que dá uma uniformidade ao trabalho, sendo os ganhos indiscutíveis. O fato de as professoras estarem há muitos anos 
trabalhando na escola foi importante para que a escola fosse crescendo como coletivo. O trabalho foi desenvolvido em conjunto, como salienta a professora Rosa:

\begin{abstract}
A professora de matemática, de geografia, a diretora, a vice-diretora, a coordenadora, muitas colegas já trabalhavam aqui. Quer dizer, o grupo fez a escola crescer, porque nem tudo que tem aqui foi dado pelos governos. Foi a direção, pais e professores que conseguiram, que fizeram com que a escola crescesse. [...] E a presença dos professores desde o início da escola; en cheguei mais tarde, mas há professores que estão aqui desde o início da escola, porque a nossa escola foi crescendo junto com eles.
\end{abstract}

Essa passagem é uma forte demonstração das teses desenvolvidas por Ball (1994) e Ball, Maguire e Braun (2012). Na primeira referência, o autor desenvolve a tese do ciclo de políticas e da política como discurso. Nesse trabalho, Ball formula a tese, importante a ser destacada, de que as políticas não têm garantias; são contingentes, são produzidas e retrabalhadas com novos significados, reconstruídas discursivamente ao se defrontarem com os diferentes contextos e processos recontextualizadores (no exemplo, as escolas Amarela e Verde). Outros sentidos de formulação das políticas que são reformuladas por meio de processos de resistência e de luta que se estabelecem nos diferentes níveis recontextualizadores. Juntamente com Maguire e Braun, Ball desenvolve a tese de como as escolas fazem as políticas, mostrando no contexto da prática, como as políticas são permanentemente ressignificadas pelas escolas como atuantes no processo educativo - docentes, equipes diretivas, comunidades, estudantes.

Quanto à liberação dos professores para a participação em cursos de formação continuada, ambas as escolas os incentivam e liberam para cursos de formação ou capacitação, como segue:

\footnotetext{
Quando há cursos de capacitação para os professores a nossa escola libera os professores sempre que são convidados ou convocados, e não é o caso da maioria das escolas. É por isso que eu te digo que o trabalho aqui na escola é em conjunto com os professores. Se um professor é convidado para fazer um curso da SMED, outro professor assume as suas aulas, se não tiver outro professor a direção vai para sala de aula e o professor é liberado para fažer o curso, então este é um diferencial (gestora Maria; EA)

Bem, na medida do possivel a gente libera os professores, mas dai vai um representante e ele traz o que foi conversado, para a escola no dia da reunião pedagógica a gente sempre procura liberar (Gestora Neusa; EV).
}

Notamos que, embora as duas gestoras concebam a importância da formação, parece-nos que as condições de uma e outra escola apresentam nuances no que se refere à liberação para cursos, que podem ser ressaltadas. Enquanto na primeira há uma determinação objetiva de estimular e facilitar a formação docente, na segunda, isso é favorecido na medida do possível. As razões não 
são evidentes, mas podemos inferir que o número de professoras, as condições de trabalho, o tamanho das turmas podem ser fatores que influenciem a política de cada escola. No entanto, quanto à participação dos gestores nos cursos de formação promovidos pela SMED, podemos observar melhor essas diferenças entre as escolas, como segue:

Eu sempre participei, todos os anos têm cursos para os gestores. Eu não percebo muita diferença, como já estou na direção há bastante tempo eu não vejo que acrescente muita coisa, porque tudo o que eles falam nós já estamos fazuendo, a gente já conhece, mas é claro que a cada ano vem se renovando, sempre vai ter uma melhora (Gestora Maria; EA).

Dentro do possivel a gente participou, mas às vezes en acho que os cursos da secretaria trazem uma realidade muito diferente daquela da nossa escola [...] a gente não tem o tempo disponivel para essa formação, aqui na escola a gente é secretária, é diretor, às vezes é o conselheiro do aluno, é o que tem que sair para fazer as compras, é quem tem que fazer a prestação de contas. Enfim o que se consome de tempo..., tu não tens tempo de ficar num curso, às vezes tu até que participas de um curso de formação mas como é que tu vais deixar uma ou duas pessoas só aqui na escola, não tem como (gestora Olga; EV).

A partir dos relatos acima, podemos perceber que, embora a gestora Maria tenha certa ressalva em relação aos cursos de formação, ela leva em consideração o que foi discutido nos cursos para o desenvolvimento das atividades da escola. Já o relato da gestora Olga demonstra que ela não dá tanta relevância aos cursos de formação e sua participação ocorre dentro das possibilidades do trabalho desenvolvido na escola; não há um planejamento para as gestoras poderem participar dessas atividades. No caso da gestora Olga, há uma indicação da distância entre o conteúdo dos cursos e a realidade das escolas, o que pode ser um fator de desinteresse.

Da mesma forma, a relação das gestoras com a SMED apresenta diferenças significativas entre as escolas:

Eles estão bem focados na educação, este ano temos a Prova Municipal, e assim, eles têm procurado dar o melhor para as escolas, agora no início do ano letivo o Secretário nos ligou para saber se estava começando bem, se tínhamos todos os professores, para saber sobre as condições físicas ... (gestora Maria; EA)

Existe um diálogo aberto, a gente sempre busca pela SMED, qualquer dívida a gente busca pela SMED, às vezes somos atendidos, outras vezes não. Agora, para atender alguns professores, a gente busca pela SMED, independente da administração, a escola sempre teve um bom diálogo (gestora Amélia; EA).

Eu dificilmente vou até a SMED, sou uma pessoa que não sou muito de estar na SMED, porque eu acho que se o problema está aqui, a gente tem que tentar resolver aqui, não adianta eu ir lá contar o problema, por que eu sei que não vai resolver (gestora Olga; EV).

Olha, eu acho que a SMED tenta ajudar as escolas no que ela pode, na formação, se a gente precisa que eles venham na escola, eles vêm, eles têm feito formação continuada, a gente tem reuniões com a supervisão pedagógica (gestora Neusa; EV). 
A SMED tem um papel significativo para as gestoras da Escola Amarela e, sempre que necessário, as gestoras entram em contato com a Secretaria. Nesse caso, parece-nos que há uma retroalimentação, no sentido de buscar uma coerência entre as políticas e as ações - "saímos bem no IDEB", "reforçamos as políticas e vice-versa" (o Secretário liga para a melhor escola no IDEB para saber como vão as coisas por lá). Já os relatos das gestoras da Escola Verde demonstram um distanciamento entre a escola e a SMED; ainda que a gestora Neusa considere positivas as ações da SMED, não se percebe um envolvimento entre da escola e a secretaria. No entanto, esse fenômeno pode ter como causa os sentimentos que as gestoras possuem em relação ao tratamento dado a sua Escola:

\begin{abstract}
Assim, olha... Cada reunião que eu vou eu sinto muita vergonha, quando eu chego na escola en comento com as gurias, com a vice-diretora, com as coordenadoras e comento com as professoras, que eu não aguento mais ir em reuniões que o prefeito fala sempre das escolas que envergonbam o município [...]. Eu como gestora sinto muito orgulho de ser desta escola, se ela envergonba a cidade azar do prefeito que não conhece a realidade do município dele (gestora Olga; EV).

O que mais me deixa triste é ouvir o prefeito dizer que as escolas que possuem baixo indice envergonham ele e o municíio, a gente não gostaria que fosse assim, mas a realidade que a gente tem é essa, a gente tenta mudar através de estudos, através de reuniões, através de metodologias diferentes para os alunos, mas é difícil (gestora Neusa; EV).
\end{abstract}

Os depoimentos das gestoras demonstram sua insatisfação em relação ao modo como as escolas com baixo IDEB são referidas nos discursos do prefeito. Como as ações da SMED fazem parte do plano municipal de governo, baseado no modelo gerencial da NGP, centrado nas avaliações, metas, resultados e incentivos, isso pode influenciar a relação das gestoras com a secretaria. As gestoras não se sentem confortáveis para participar das atividades promovidas pela SMED, assim como apresentavam certa rejeição ou resistência ao que era proposto pela secretaria.

\title{
CONSIDERAÇÕES FINAIS
}

O que podemos observar em muitos municípios e cada vez mais com muita frequência é a adoção de políticas orientadas para a NGP e avaliação em larga escala, não só no sentido de adotar as políticas induzidas pelo estado, tanto em nível federal quanto estadual, mas igualmente com a criação de sistemas próprios de avaliação em larga escala, com provas municipais e políticas de bônus salarial para o magistério, como é caso do município investigado.

Confirmamos que programas com metas baseadas em lógicas métricas, com exames padronizados, índices de desempenho, padronização curricular e sistemas de avaliação podem continuar a reproduzir as desigualdades já existentes 
no sistema escolar. Políticas 'iguais' para atingir metas 'desiguais' em contextos muito diversos, como vimos e tentamos demonstrar em várias passagens deste estudo, faz com que as metas proposta não sejam atingidas para todas as escolas e todos os estudantes, já que alguns convivem com contextos desfavoráveis. Muitas professoras e gestoras entrevistadas indicam, ora diretamente ora indiretamente, que as políticas apontadas pela administração do município não contemplam as necessidades das escolas e afirmam que as desigualdades de variados tipos cultural, social e econômica - é que acabam pesando para o desempenho escolar.

Nesse sentido, embora os formuladores das políticas de avaliação insistam que a educação baseada em evidências - dados numéricos, metas, índices e padronização - vai melhorar a qualidade da educação, o que observamos quando investigamos os efeitos de tais políticas de forma qualitativa é que essa tese não se confirma. Mesmo que os índices melhorem (aumento do IDEB, por exemplo), o desempenho da educação em termos qualitativos (aprendizagem) não se confirma no contexto prático.

As políticas são recepcionadas diferentemente pelos diferentes atores em cada escola. A forma como as escolas põem em prática as políticas reafirma a tese desenvolvida por Ball de que não há garantias para as políticas educativas. Ao contrário, o que identificamos em vários contextos são contestações. Enquanto as escolas e o professorado não forem incluídos como interlocutores e reconhecidos como produtores, haverá sempre um distanciamento cada vez maior entre o que é formulado e o que é praticado nas escolas.

Por isso, afirmamos que a busca da qualidade escolar tem que considerar as desigualdades e singularidades dos diferentes contextos para ganhar em qualidade social e comprometer os atores com a formulação e execução das práticas educativas.

\section{REFERÊNCIAS}

BALL, Stephen J. Educação Global S.A.: Novas redes políticas e o imaginário neoliberal. Ponta Grossa: Editora UEPG, 2014.

Novos Estados, nova governança e nova política educacional. In: Apple, M.W., Ball, S.J. e Gandin, L.A. (org.) Sociologia da Educação - análise internacional. Porto Alegre: Penso, 2013, p.177-189.

The education debate. Bristol: The Policy Press, 2008. 
Education Reform: a critical and post-structural approach. Buckingham; Opens University Press, 1994.

BALL, S. J.; MAGUIRE, M.; BRAUN, A. How schools do policy - policy enactments in Secondary Schools. London: Routledge, 2012.

BOURDIEU, P. A escola conservadora: as desigualdades frente à escola e à cultura. Educação em Revista. Belo Horizonte (10), p. 3-15, dez. 1989.

CARVALHO, L.M. O Senhor Director: fragmentos de uma história de actores e práticas escolares em Portugal. Educação e Pesquisa, v. 26, n.2, p. 31-49, São Paulo, Jul/Dec., 2000.

DARDOT, Pierre; LAVAL, Christian. A nova razão do mundo - ensaio sobre a sociedade neoliberal. São Paulo: Boitempo, 2016.

DOURADO, L. F; OLIVEIRA, J. F. A qualidade da educação: perspectivas e desafios. Cadernos Cedes, Campinas, v. 29, n. 78, p. 201-215, maio/ago. 2009.

ENGUITA, Mariano Fernández. Educação e teorias da resistência. Educação \& Realidade, Porto Alegre, v. 14, n. 1, p. 3-15, jan/jun, 1989.

ÉRNICA, M.; BATISTA, A. A. A escola, a metrópole e a vizinhança vulnerável. Cadernos de Pesquisa, v. 42, nº 146, p. 640-666, maio/ago. 2012.

FERRÃO, M. E.; FERNANDES, C. O efeito-escola e a mudança - dá para mudar, evidências da investigação brasileira. Revista Electrónica Iberoamericana sobre Calidad, Eficacia y Cambio en Educación, v.1, n. 1, p. 1 -13, 2003.

FRANCO, C. et al. Qualidade e equidade em educação: reconsiderando o significado de "fatores intra-escolares". Ensaio: Avaliação e Políticas Públicas em Educação. Rio de Janeiro, v.15, n.55, p.277-298, abr./jun. 2007.

IVO, A. A.; HYPOLITO, A.M. Gestão educacional e o Índice de Desenvolvimento da Educação Básica da rede municipal de ensino de Santa Maria-Rio Grande do Sul. Revista Educação em Questão, Natal, v. 52, n. 38, p. 137-162, maio/ago. 2015 
LAVAL, Christian. A escola não é uma empresa: o neo-liberalismo em ataque ao ensino público. Londrina: Planta, 2004.

LESSARD, C.; CAPRPENTIER, A. Políticas Educativas - a aplicação na prática. Petrópolis, RJ: Vozes, 2016.

MAINARDES, J.; MARCONDES, M.I. Entrevista com Stephen J. Ball: um diálogo sobre justiça social, pesquisa e política educacional. Educação \& Sociedade, Campinas, vol. 30, n. 106, p. 303-318, jan/abr. 2009.

NOGUEIRA, C. et al. A influência da família no desempenho escolar: estudo de dados da geração escolar 2005. Revista Contemporânea de Educação, v. 4, n.8, p.1-18, 2009.

OLIVEIRA, D. A. Nova Gestão Pública e Governos Democrático-Populares: contradições entre a busca da eficiência e a ampliação do direito à educação. Educação \& Sociedade, v.36, n.132, Campinas, jul/set, 2015.

PALERMO, G; SILVA, D.B.; NOVELLINO, M.S.F. Fatores associados ao desempenho escolar: uma análise da proficiência em matemática dos alunos do $5^{\circ}$ ano do ensino fundamental da rede municipal do Rio de Janeiro. R. bras. Est. Pop., Rio de Janeiro, v. 31, n.2, p. 367-394, jul./dez. 2014.

PAZ, F.M.; RAPHAE, H.S. Contribuições para o debate sobre a Escola Pública: o Índice de Desenvolvimento da Educação Básica (IDEB). Colloquium Humanarum, Presidente Prudente, v. 9, n. 2, p. 55-65, jul/dez 2012.

SANTOS, L. L. Políticas públicas para o ensino fundamental: Parâmetros Curriculares Nacionais e Sistema Nacional de Avaliação (SAEB). Educação \& Sociedade, Campinas, vol. 23, n. 80, p. 346-367, Setembro, 2002.

VERGER, A.; NORMAND, R. Nueva gestión pública y educación: Elementos teóricos y conceptuales para el estudio de un modelo de reforma educativa global. Educação \& Sociedade, v.36, n.132, p. 599-622, Campinas, jul/set, 2015.

VIANA, M. As práticas socializadoras familiares como locus de constituição de disposições facilitadoras da longevidade escola em meios populares. Educação e Sociedade, v.26, n. 90, jan.-abr. 2005, p. 107-125. 
ANDRESSA AITA IVO é Professora da Universidade Federal de Santa Maria, Mestre em Educação e Doutora em Educação pela UFPel. E-mail: dessaaita@ gmail.com

ÁLVARO MOREIRA HYPOLITO é Professor da Universidade Federal de Pelotas, Mestre em Educação pela UFMG, Ph.D. em Educação pela Universidade de Wisconsin-Madison, Pesquisador 1D do CNPq, desenvolve estudos sobre Trabalho Docente, Currículo e Gestão. E-mail: hypolito@ufpel.edu.br

Recebido em outubro de 2017 Aprovado em dezembro de 2017 